\title{
Beleza Vivisseccionada e Conhecimento Detetivesco: Sobre os primeiros escritos de Marshall McLuhan ${ }^{1}$ \\ Takeshi Kadobayashi
}

Em 1954, o teórico da mídia Marshall McLuhan escreveu um artigo intitulado "Sight, Sound and the Fury" no jornal Commonweal (McLUHAN, 1954, p.7-11). McLuhan já havia publicado seu primeiro livro, The Mechanical Bride (1951), quando escreveu este ensaio, cujo título é um trocadilho com o do romance de William Faulkner, ele mesmo uma alusão a Shakespeare. Contudo, o momento ainda não havia chegado quando publicaria em sequência seus mais importantes trabalhos, The Gutenberg Galaxy (1962) e Understanding Media (1964), que o tornariam uma celebridade em mídia. Apesar disso, a junção de palavras como "visão" e "som" nesse título nos lembra da visão midiática da história que ele desenvolveria mais tarde em The Gutenberg Galaxy. Na verdade, esse pequeno ensaio, com o subtítulo "As Novas Mídias da Comunicação de Massa Estão Tendo Efeito Revolucionário na Sociedade e na Cultura", possui vários motivos que antecipam as teses sobre mídia que ele desenvolveria posteriormente, tornando o artigo particularmente interessante na retrospectiva do desenvolvimento de seu pensamento.

A década de 1950 é o período em que McLuhan foi mais longe nas abordagens sobre mídia que apresentou em The Mechanical Bride, e o processo desse desenvolvimento pode ser traçado a partir de seus numerosos artigos, publicados no jornal transdisciplinar Explorations (editado por McLuhan e Edmund Carpenter, um antropólogo), entre outros. Um aspecto particularmente notável nesse desenvolvimento, no qual "Sight, Sound and the Fury" foi uma importante contribuição, é o comprometimento de McLuhan com o modernismo literário, indicado no próprio título do artigo. McLuhan, que havia estudado Literatura Inglesa sob orientação de I. A. Richards em Cambridge, publicou muitos artigos e resenhas em revistas de crítica literária como The Sewanee Review nos anos 40 e 50. Ressalta-se repetidamente que o método da Nova Crítica que ele cultivou nessas experiências teve importante significado nas reflexões sobre mídia que ele desenvolveria mais tarde: isto é, a atitude da Nova Crítica, que limita o objeto da crítica à obra em si, apresentada como texto, e se recusa a fazer incidir na interpretação a imagem do autor por trás dele, resultando em um formalismo que possibilitou o método de McLuhan, no qual ele lê as expressões midiáticas dadas por numerosos autores anônimos por meio de suas formas (“o meio é a mensagem”). ${ }^{2}$

Entretanto, a perspectiva dada pela reflexão de McLuhan sobre a mídia a partir da literatura modernista e da crítica não é limitada a isso. "Sight, Sound and the Fury" começa com as seguintes palavras: 
Em sua recente visita aos Estados Unidos, Roy Campbell mencionou que, quando Dylan Thomas descobriu que poderia ler poesia no rádio, isso mudou sua poesia para melhor. Thomas descobriu uma nova dimensão em sua linguagem quando estabeleceu uma nova relação com o público.

Até Gutenberg, publicações de poesia significavam ler ou declamar o poema de alguém para um pequeno público. Quando a poesia começou a existir primordialmente na página impressa, no século 17, ocorreu a estranha mistura de visão e som conhecida depois como "poesia metafísica", que tanto tem em comum com a poesia moderna. (McLUHAN, 1954, p.7)

Por trás de seu gesto de situar os poetas metafísicos como John Donne e George Herbert entre as culturas oral e literária, podemos ver a sombra do poeta do alto modernismo, T.S. Eliot. Em seu famoso ensaio, "The Metaphysical Poets" (1921), Eliot avalia os poetas metafísicos como sendo a última geração que poderia atingir uma unidade de pensamento e de sentimento no século 17, quando a "dissociação da sensibilidade", que perdura até o presente, se estabeleceu (ELIOT, 1932, p.241-250). Na citação acima, McLuhan parece reformular essa idéia de Eliot a partir do ponto de vista da transição de uma forma da mídia que transmite a poesia para outra.

Com efeito, é indiscutível que a frequente utilização do termo "sensibilidade" é um dos elementos que caracterizam os primeiros escritos de McLuhan sobre literatura. Por exemplo, em "Edgar Poe's Tradition" (1944), que é um de seus primeiros textos, desconsiderando-se os dos tempos de estudante, ele descreve Poe da seguinte maneira:

Quando morreu, em 1849, não havia escritor na Inglaterra ou nos Estados Unidos que não estivesse, em comparação com ele, explorando uma consciência meramente local e uma resposta meramente local às tensões psicológicas da época. Entretanto, a organização de sua sensibilidade, com seus deslocamentos e inadequações, nunca é secundária, mas autêntica e em primeira-mão.(McLUHAN, 1944, p.24)

É difícil não reconhecer aqui um eco da famosa frase de Eliot em "The Metaphysical Poets": "No século 17 se estabeleceu uma dissociação da sensibilidade, e dela nós nunca nos recuperamos" (ELIOT, 1932, p.247). Ou seja, para McLuhan, assim como para Eliot, a vocação do poeta é evidenciar a unidade da sensibilidade na era da "dissociação", e ele louva Poe a partir desse ponto de vista. Várias páginas depois, McLuhan toma um não menos famoso artigo de Eliot, "Tradition and the Individual Talent” (1917), como um suporte por trás da experiência da dissociação da Europa e dos Estados Unidos.

Desnecessário dizer que, ao investigar essas genealogias, eu não tenho a intenção de reduzir as idéias de McLuhan a um apanhado de relações e influências. Ao invés disso, devemos deixar claro como os conceitos originais de McLuhan foram por ele elaborados. Notável nessa consideração é o fato de que, na passagem de "Sight, Sound and the Fury" citada anteriormente, ele destaca a transição da mídia da poesia da oralidade para a forma impressa como base da "estranha mistura de visão e som" na poesia metafísica. $O$ que é importante ao se considerar a teoria de mídia de McLuhan no contexto da crítica literária é desenredar o desenvolvimento de idéias que antecipam The Gutenberg Galaxy. 
Uma passagem de um outro artigo, chamado "Joyce, Mallarmé, and the Print", é útil para fazer avançar esse exame.

\begin{abstract}
Em seu recente estudo sobre George Herbert, Rosamund Tuve destaca a extensão à qual os conceitos metafísicos eram traduções em termos verbais das imagens pictóricas populares do final da idade média. Ela foi capaz de demonstrar que os conceitos característicos de Herbert e de outros surgiram do encontro da velha cultura de manuscrito (com suas imagens marginais) e a nova mídia impressa. [...]

Portanto, se os metafísicos devem tanto à adaptação dos pictogramas medievais para o meio impresso, poderia ser sugerido que a poesia moderna, com seus elaborados cenários mentais, deve muito à nova tecnologia pictórica que fascinou Poe e Baudelaire, e sobre a qual Rimbaud e Mallarmé desenvolveram muito de suas estéticas.(McLUHAN, 1943, p.39)
\end{abstract}

Aqui, assim como em "Sight, Sound and the Fury", ele destaca o "encontro" de diferentes mídias. Ademais, essa operação de situar a poesia metafísica entre a cultura medieval do manuscrito e a nova cultura do impresso está conectada ainda ao "encontro" da mídia em outra era: aquela da tipografia e de novos meios pictóricos como a fotografia e o panorama. Portanto, considerando que eles estão situados entre meios pictóricos e meios literários, os poetas metafísicos são aqui justapostos, embora em diferentes direções, com poetas modernos de Poe a Mallarmé.

A justaposição da configuração de diferentes períodos, evidentemente, é um método que imediatamente remete a Ulisses, de James Joyce, que justapõe o épico de Homero e um dia na Dublin moderna, especialmente a partir da resenha escrita por Eliot, que tornou esse ponto de vista influente (ELIOT, 1975, p.175-178). Essa idéia oferece um importante método para o estilo de McLuhan descrever a mídia. De fato, embora The Gutenberg Galaxy aparentemente leve o estilo de descrição histórica de períodos antigos a novos, seu dinamismo está mais calcado na justaposição de configurações em diferentes épocas. Esse livro, composto de vários capítulos curtos, traça, por um lado, uma rota em ziguezague entre o encontro das culturas oral e literária na Grécia Antiga, e, por outro lado, a de culturas manuscrita e impressa; assim, o novo encontro da mídia na contemporaneidade é ainda mais sobreposto nessas configurações.

1.

Como forma de retomar de forma ordenada o argumento desenvolvido até aqui, convém retomar uma citação anterior de "Sight, Sound and the Fury", na qual há um episódio de leitura de poesia no rádio que ajuda na possibilidade de que o "encontro" com um novo meio gere novas formas de expressão na literatura. Já mencionei anteriormente que esse tipo de idéia de McLuhan se origina no modernismo literário, o que, por sua vez, é refletido em sua própria leitura desse modernismo. Ele discute esse ponto de vista mais uma vez na parte final do mesmo artigo; isto é, sua apreciação de James Joyce é relativa à exploração de novas formas de expressão, ao ser comparado com Ezra Pound e T.S. Eliot, como é citado no seguinte trecho:

Mas o leitor que aborda Pound, Eliot e Joyce de forma parecida, como exploradores dos aspectos cinemáticos da linguagem, chegará à apreciação mais rapidamente do que aquele que inconscientemente tenta buscar sentido reduzindo o uso que fazem dos novos meios de comunicação às abstratas formas lineares de uma página de livro.(McLUHAN, 1954, p.9) 
Quando um novo meio aparece e colide com o antigo ambiente midiático, o artista rapidamente explora nesse conflito as possibilidades do novo meio e as apresenta como uma nova forma de expressão. Nesse aspecto, este não é diferente do argumento contido na citação anterior. O que é diferente é o fato de o cinema ser apresentado aqui como uma nova mídia, e por isso McLuhan não parece ir mais longe ao afirmar que poetas do século 20 são inspirados pela mídia do século 20 da mesma forma que os poetas do século 19 foram inspirados pela mídia do século 19. ${ }^{3}$ Entretanto, nessa definição dos modernistas literários como "exploradores dos aspectos cinemáticos da linguagem”, há uma idéia de compreensão estética - tanto no sentido de percepção da beleza como em um antigo sentido de estesia, isto é, sensibilidade - que não pode ser reduzida a esse tipo de enquadramento. A citação continua assim:

\begin{abstract}
O fato básico que se deve perceber sobre a câmera e o projetor de filmes são suas semelhanças com os processos de cognição do ser humano. Essa é a fonte real de seus poderes mágicos e transformadores. [...] A câmera registra e analisa o mundo diurno com uma intensidade mais do que humana por causa do ângulo de quarenta e cinco graus de sua lente. O projetor revela esse mundo diurno em uma tela escura, onde ele se torna um mundo de sonhos. A fantástica semelhança disso tudo com a cognição humana se estende ao menos até este ponto: na cognição nós interiorizamos o mundo exterior. Nós temos de recriar na mídia de nossos sentidos e estruturas internas o drama da existência. Esse é o trabalho do logos poietikos, o intelecto ativo. $\mathrm{Na}$ fala, nós proferimos esse drama que re-criamos analogamente dentro de nós. (McLUHAN, 1954, p.9)
\end{abstract}

O mecanismo pelo qual um filme registra o mundo e o projeta na tela é descrito aqui numa analogia com a cognição e a fala humanas. Devemos notar que a analogia vai do aparato cinemático até a ação cognitiva humana, e não no sentido contrário. Se esquecermos a direção dessa analogia, na qual nossa cognição é entendida de modo a proceder como se o cinema registrasse e apresentasse novamente o mundo, e tal analogica for compreendida de modo a haver uma relação analógica entre a cognição humana seguramente definida e o aparato cinemático, identificaríamos também nesse tipo de raciocínio uma falácia de perspectiva nietzschiana que confunde causa e efeito. Se o cinema parece revelar os segredos de nossa cognição, é apenas porque o mecanismo do aparato cinemático apresenta um modo de compreender nossa ação cognitiva na dimensão da imaginação que ele faz surgir.

Ora, essa atenção para a analogia entre o aparato cinemático e a ação cognitiva humana resulta em outro ponto de vista: a saber, quando McLuhan vê em Joyce uma exploração dos "aspectos cinemáticos da linguagem", isso significa ao mesmo tempo que a expressão linguística de Joyce explora a ação cognitiva humana.

Porque na cognição em si reside o todo do processo poético. Mas o artista difere da maioria dos homens em seu poder de prender e, então, reverter os estágios da compreensão humana. Ele aprende como incorporar os estágios da cognição (o "plano" de Aristóteles) em uma obra exterior, podendo ser prolongados para a contemplação. (McLUHAN, 1954, p.9)

Ou seja, para McLuhan, a ocupação do artista é desenvolver o processo poético que já reside dentro da própria cognição humana, para então incorporá-lo à obra de arte. Ainda que não haja menção direta, não é um salto abrupto associar esse ponto de vista com a técnica de "fluxo de consciência", frequentemente mencionada em conexão com 
Joyce. Em primeiro lugar, o título desse ensaio está relacionado com O som e a fúria, de Faulkner, considerada uma das principais obras a empregar a técnica de "fluxo de consciência".

"Fluxo de consciência" ou "monólogo interior" é uma técnica que expressa aproximadamente na forma textual o processo de pensamento do personagem pelo uso constante de discurso indireto livre; Joyce, Faulkner e Virginia Woolf são conhecidos como mestres dessa técnica. É frequentemente salientado que a idéia dessa técnica tem origem na filosofia de William James e Henri Bergson, que compreendem nosso processo mental pela duração do tempo, e a própria frase "fluxo de consciência" deriva de The Principles of Psychology (1890), de William James. Entretanto, por mais que tenhamos destacado estudos, não devemos confundir o "fluxo de consciência", como uma técnica literária, com o processo mental que deve ser interpretado pela filosofia ou pela psicologia. ${ }^{4} \mathrm{O}$ "fluxo de consciência" na literatura nada mais é do que uma técnica que analogicamente expressa o que parecem ser os processos da consciência humana e, se nós equivocadamente considerarmos isso um processo próprio de consciência, correremos o risco de cair na enganosa perspectiva que vimos na analogia entre cinema e cognição. Agora, ao assumirmos essa posição, isso deveria nos leva a detectar a mesma falácia na afirmação de McLuhan de que "na própria cognição está a totalidade do processo poético", que o artista incorpora ao seu trabalho? Antes de concluir rapidamente desse modo, desejo acompanhar a clássica definição de "fluxo de consciência" de William James.

James começa o capítulo 9, "The Stream of Consciousness," de The Principles of Psychology criticando o postulado geral da psicologia segundo o qual o estudo da mente deve começar pelas sensações "como os feitos mentais mais rudimentares" e construir os estados mais avançados da mente a partir de suas sínteses. A partir desse ponto de vista de construir uma psicologia empiricamente baseada, James insiste que a única coisa que um psicólogo pode assumir como fato no início da investigação é o próprio processo de pensamento.

Oprimeiro fato para nós, então, como psicólogos, é que algum tipo de pensamento ocorre. Utilizo a palavra pensamento [...] para toda forma de consciência, indiscriminadamente. Se pudéssemos dizer em inglês "pensa", como dizemos "chove" ou "sopra", nós poderíamos situar o fato mais facilmente com o mínimo de suposição. Como não podemos, nós simplesmente dizemos que o pensamento ocorre. (JAMES, 1952, p.224-225)

Aqui, James manifesta sua resolução de eliminar até mesmo o postulado da subjetividade em sentido gramatical com o objetivo de abordar a exata experiência do pensamento, e ele parece ir até o ponto de dizer que nossa linguagem cotidiana é insuficiente para esse propósito. A partir disso, nós podemos concluir que "o fluxo de consciência", como o processo de pensamento que James investiga, pertence à dimensão que excede a relação representativa com a expressão linguística, e isso deve ser diferenciado rigidamente do "fluxo de consciência" enquanto prática linguística dos modernistas literários. Como nós já vimos, essa ressalva - de que o método literário do "fluxo de consciência" não representa o processo de pensamento - é um pressuposto básico quando alguém o aborda de um ponto de vista acadêmico. É essa ressalva que torna possível assegurar o espaço aberto 
pelas obras literárias como um campo livre da demanda por verdade "científica", e que examina "o fluxo de consciência" como uma prática linguística em tal espaço sem ser incomodado pela questão que discute se ele verdadeiramente representa o fenômeno da consciência de maneira precisa.

Entretanto, uma análise mais criteriosa revela outra possibilidade. A assertiva de James é a seguinte: se a expressão "pensa” for permitida, esta é mais capacitada a expressar o processo de nosso pensamento sem pressuposições desnecessárias; contudo, nossa linguagem cotidiana apenas aprova a expressão "o pensamento ocorre". Isso quer dizer que, se nós podemos eliminar a restrição do dia-a-dia e dizer "pensa", isso expressa o processo de pensamento de forma mais precisa. A partir desse ponto de vista, a afirmação de James aqui tem a mesma tendência de uma corrente do modernismo literário que procura representar o irrepresentável, o próprio processo de consciência, por meio da reformulação da expressão linguística - o "fluxo de consciência" é o próprio nome dessa corrente. Ademais, a expressão linguística "pensa" deriva de expressão impessoal comum, como "chove" ou "sopra". Além disso, aparentemente, a tentativa de abordagem de James sobre "o fluxo de consciência" é ela mesma situada na dimensão da expressão linguística do início ao fim. A passagem seguinte, na qual a frase "o fluxo de consciência" aparece primeiro, reforça esta interpretação.

A consciência, então, não surge a si mesma como completamente fragmentada. Palavras como "corrente" ou "sequência" não a descrevem de maneira adequada como elas se apresentam num primeiro momento. Elas não são articuladas; elas fluem. Uma "correnteza" ou um "fluxo" são metáforas pelas quais ela é mais naturalmente descrita. Daqui por diante, vamos chamar a isso de fluxo de pensamento, de consciência, ou de vida subjetiva. (JAMES, 1952, p.239)

O que James antevê aqui como psicologia empírica é, de um certo ponto de vista, buscar as metáforas apropriadas para as várias facetas da experiência de nossa consciência. Essa investigação precisa necessariamente se apoiar na linguagem. James diz, por exemplo:

Nós devemos expressar uma sensação de $e$, uma sensação de se, uma sensação de mas, uma
sensação de por, tão prontamente como expressamos uma sensação de fossa ou uma sensação
de frio. Porém, nós não o fazemos: nossos hábitos de reconhecer a existência das partes
substantivas separadamente se tornaram um hábito tão inveterado que a linguagem quase se
recusa a deixar-se ter qualquer outro uso. (JAMES, 1952, p.245-246)

Aqui, James faz uma distinção entre as "partes substantivas" e as "partes transitivas" da consciência, e critica que os filósofos tenham até aqui excluído este segundo estado - ou seja, o estado de consciência que não repousa sobre algumas idéias ou sensações comparativamente fixas - de seus objetos de análise. De acordo com James, eles falharam em compreender as partes transitivas da consciência porque não puderam reconhecer a possibilidade de sentir diretamente "as inumeráveis relações e formas de conexão entre os acontecimentos do mundo" (JAMES, 1952, p.244). Isto é, eles se recusaram a usar a linguagem para a cognição de entidades transitivas. Contra essa tendência, James afirma: 
Não há uma conjunção ou uma preposição, e dificilmente uma frase adverbial, forma sintática ou inflexão de voz, na fala humana, que não expressa nuances ou outra relação em que em algum momento nós de fato sentimos existir entre os grandes componentes do nosso pensamento. (JAMES, 1952, p.245)

Isto é, nossa linguagem cotidiana expressa precisamente as partes transitivas da consciência, ou "o fluxo de consciência", e a limitação da linguagem filosófica é que nós não possamos expressá-las como "um sentimento de" alguma coisa: em outras palavras, para compreendê-las como entidades que possam ser objeto da cognição. Entretanto, não haveria uma auto-contradição nesse tipo de discussão, pois, apesar de James parecer demonstrar o fenômeno da consciência como objetos que excedem a limitação da compreensão linguística, ele não continua a se refugiar em metáforas linguísticas para descrever a natureza de tais fenômenos da consciência? Portanto, surge aí uma suspeita de que, apesar disso indicar que James tenta abordar o fenômeno da consciência de maneira mais próxima, ele apenas propõe trocar as metáforas linguísticas de consciência propostas por filósofos anteriores por outras metáforas que ele espera que sejam mais persuasivas.

Evidentemente, não tenho a intenção de denunciar o sofisma de James com essa discussão, uma vez que todas as investigações filosóficas em última instância não têm outra saída senão a de encontrar suas expressões na linguagem, e de qualquer modo, um novo exame sistemático da filosofia de James excede meu propósito aqui. O que desejo destacar nesse longo desvio são preferencialmente as potencialidades que a metáfora do "fluxo de consciência" trazem para abrir um novo campo de expressão linguística. Essas potencialidades repousam exatamente no caráter auto-contraditório da discussão de James, e, a esse respeito, não é próprio fazer uma distinção clara entre a construção filosófica de linguagem por James e a expressão literária dos modernistas.

Destaquei anteriormente a possibilidade de que McLuhan corre o risco de incorrer em uma perspectiva falaciosa ao falar da cognição humana em analogia aos aparatos cinemáticos, bem como do processo poético como uma ação criativa por parte dos artistas análoga à cognição. A falácia de McLuhan compartilha do mesmo tipo de auto-contradição que vimos em James. Ou seja, apesar de aparentemente apresentar um entendimento analógico da cognição humana com o modelo dos aparatos cinemáticos, a direção da analogia é revertida em algum ponto; as discussões continuam como se fosse exatamente a expressão literária feita pelos modernistas que explorasse "os aspectos cinemáticos da linguagem", que revelasse os segredos da cognição humana como um processo poético. Entretanto, meu objetivo aqui não é rejeitar tal estrutura auto-contraditória simplesmente como falaciosa, mas dirigir o olhar para as possibilidades positivas que esse tipo de estrutura pode trazer à dimensão da imaginação. Esse ponto de vista torna possível jogar uma luz sobre as reflexões trazidas pela estética do modernismo à investigação que McLuhan faz da mídia.

Em direção a esse propósito, sintetizo aqui o esquema de compreensão estética em McLuhan que extraí de "Sight, Sound and the Fury". (1) No processo de cognição humana, existe um "processo poético" ou um "drama de existência" que é análogo ao processo no qual os aparatos cinemáticos registram o mundo e o projetam novamente. (2) O que o artista realiza na criação do trabalho artístico é o ato de "prender" as etapas 
desse "processo poético" de cognição e sua "incorporação" à obra de arte. Da forma como mostrei, existem influências dos modernistas literários por trás das abordagens de McLuhan. A seguir, avançarei nessa interpretação com especial atenção a James Joyce e Edgar Alan Poe, dois autores cujos nomes já enfatizei.

2.

A criação artística é análoga ao processo de cognição humana, e a obra de arte é a própria captura do processo poético de cognição. Com o objetivo de interpretar mais precisamente o que se quer dizer com esse tipo de tese, continuo a citar "Joyce, Mallarmé, and the Press". Seguindo a discussão de que o "encontro" de diferentes mídias trazem adiante uma nova forma de expressão artística, aqui já mencionada, McLuhan menciona o nome de Platão, que estava situado entre as culturas oral e literária, e diz:

Desde então [a época de Platão] nós passamos por revoluções suficientes para saber que cada meio de comunicação é uma forma de arte única que salienta um grupo de possibilidades humanas ao custo de outro. Cada meio de expressão modifica profundamente a sensibilidade humana de maneiras primordialmente inconscientes e imprevisíveis. (McLUHAN, 1943, p.40)

Esta é uma discussão que antecipa as duas teses que serão desenvolvidas em Understanding Media: a saber, a tese de que toda nova mídia muda o "sentido de proporção" do homem ao destacar um sentido de um órgão em particular, e a tese de que a mensagem de um meio não se apóia sobre seu conteúdo, mas sobre sua forma ("o meio é a mensagem"). Os aspectos significativos para nós nessa citação são as afirmações de que todo meio é uma forma única de arte, e que a alteração da sensibilidade humana por um meio permanece "inconsciente". Várias linhas depois, destacando a "inevitável retração psíquica” trazida à frente pela alfabetização, McLuhan argumenta dessa forma:

\begin{abstract}
Mas isso [a comunicação alfabética] garante uma porção de vantagens. A retração psíquica é automática, porque o processo de alfabetização é o processo de estabelecer um monólogo interior. Esse é o problema de tradução de um processo auditivo para um visual e seu contrário, que é o processo de escrita e de leitura, que traz o monólogo interior para a existência, como podemos observar nos estudo de culturas pré-alfabetizadas hoje em dia. (McLUHAN, 1943, p.40)
\end{abstract}

O que gera o "monólogo interior" é o processo de tradução entre o auditivo e o visual que faz a mediação entre a escrita e a leitura. Essa idéia está associada à observação feita por McLuhan em outra ocasião: de que o estabelecimento do hábito da leitura em silêncio coincide com a tecnologia de Gutenberg e, antes disso, ler significava ler em vOz alta (McLUHAN, 1962). Em outras palavras, contrariamente à cultura de manuscritos da idade média, que resguardou em alguma medida tradição oral, a tecnologia tipográfica completou exaustivamente a tendência da tecnologia do alfabeto fonético de reduzir o discurso a puros elementos auditivos e substituí-los por signos visuais vazios de significado. O hábito da leitura silenciosa é o efeito desse processo de tradução entre os sentidos visual e auditivo, e a interiorização desse processo ("retração psíquica") possibilita que se entenda o significado de signos visuais alinhados numa 
página impressa sem pronunciá-los por meio de uma operação automática de convertê-los em elementos auditivos, insiste McLuhan.

Com tal idéia em mente, podemos entender o uso que McLuhan faz da frase "monólogo interior" numa analogia à leitura silenciosa: se a leitura silenciosa é um processo de leitura sem a elocução, o monólogo interior é o processo de pensamento sem a elocução. Isso leva à conclusão de que o processo de contemplação sem a elocução é possibilitado como efeito da tecnologia do alfabeto. Não se pode pensar sem falar até que o processo de tradução pela tecnologia do alfabeto entre os sentidos auditivo e visual esteja estabelecido. Para dizer isso com uma expressão quase equivalente, a tecnologia do alfabeto desenvolveu a idéia de que o processo de pensamento está sempre estruturado linguisticamente de antemão, mesmo quando é expressado pela elocução.

A partir dessa interpretação radical, pode-se concluir que o "monólogo interior" ou o "fluxo de consciência" como uma técnica modernista de literatura é uma forma de expressão literária que explora totalmente a "forma de arte" do meio de alfabeto fonético e o processo de pensamento linguisticamente estruturado como uma modificação para a qual ele inconscientemente compele a sensibilidade humana. Entretanto, como já vimos, McLuhan considera os modernistas literários admiráveis, antes de mais nada, porque exploraram uma nova forma de expressão a partir do encontro entre o antigo meio tipográfico e a nova mídia visual. A idéia de McLuhan de apreensão estética também é elaborada a partir da discussão que situa Joyce como explorador dos "aspectos cinemáticos da linguagem" no contexto das passagens citadas. Portanto, parece haver uma contradição na interpretação acima, que vê a idéia de "monólogo interior" ou "fluxo de consciência" como um efeito da alfabetização.

Obviamente, meu propósito aqui não é necessariamente apresentar o corpus completo dos textos de McLuhan como uma arquitetura não-contraditória. Em primeiro lugar, é impossível oferecer uma interpretação consistente de todos os textos que foram escritos em diferentes ocasiões. Contudo, quero dar continuidade à leitura destes textos, mantendo-me fiel à direção da interpretação acima, que foi elaborada com o propósito de descrever a compreensão estética presente nos primeiros escritos de McLuhan. Destacando que Finnegans Wake, de Joyce, é uma variação do tema acima mencionado, a "retração psíquica" produzida pela alfabetização, McLuhan propõe:

\footnotetext{
Sua apresentação "verbivocovisual" de um "cinematógrafo noticioso noturno" é a primeira dramatização do próprio meio de comunicação simultaneamente como forma e veículo do fluxo de culturas humanas. A maioria dos problemas na leitura de Wake se dissolve quando se nota que ele está usando os próprios meios como formas de arte como em uma "cidade phantasma phalsificada de philme pholclórico”. (McLUHAN, 1943, p.40)
}

Desnecessário dizer, uma expressão linguística em Finnegans Wake como “cidade phantasma phalsificada de philme pholclórico" só ganha significado ao ser lida em voz alta. Nas palavras de McLuhan, ela é uma expressão "verbivocovisual" que utiliza o próprio processo de tradução entre os sentidos visual e auditivo como forma artística. Desta maneira, o que é alcançado em Finnegans Wake, para McLuhan, é a demonstração do próprio processo de "monólogo interior" que a mídia do alfabeto fonético compele inconscientemente. É significativo que, referindo-se a Joyce, McLuhan direcione a atenção 
ao cinema, mencionando frases como "cinematógrafo noticioso" e "philme". Para Mcluhan, a nova forma de expressão explorada em Finnegans Wake serve para demonstrar à mente consciente o processo inconsciente do "monólogo interior", como se o cinema desenvolvesse na tela as imagens que foram registradas em filme e exibidas num rolo de película. Em outras palavras, trata-se de trazer à consciência o processo inconsciente compelido pelo meio literário pré-existente. Esta é precisamente a forma de expressão possibilitada pelo encontro com o novo meio do cinema, e Joyce foi considerado, nesses termos, um explorador dos "aspectos cinemáticos da linguagem". McLuhan continua:

Mas a captura do fluxo de pensamento e fala que é a página escrita permite a análise prolongada do processo de pensamento do qual surge a estrutura da ciência. (McLUHAN, 1943, p.41)

Não seria um exagero interpretativo conceber "o fluxo de pensamento e da fala" como "fluxo de consciência", e então como "monólogo interior". O processo inconsciente de "monólogo interior" é trazido à consciência ao ser desenvolvido como texto escrito. Ademais, McLuhan diz que essa "análise prolongada"está relacionada com a estrutura da ciência. Antecipando-me, vou caracterizar essa estrutura da ciência mais tarde como vivisseccionada e detetivesca. Na parte conclusiva desse artigo, McLuhan cita Stephen Hero, um manuscrito de Joyce publicado postumamente.

O espírito moderno é vivisseccionado. A vivissecção propriamente dita é o processo mais moderno que se pode conceber. [O antigo espírito aceitou os fenômenos de maneira pouco garbosa. O método antigo investigou a lei com o farol da justiça, a moralidade com o farol da revelação, a arte com o farol da tradição. Mas todos esses faróis têm propriedades mágicas: eles transformam e desfiguram. O método moderno examina seu território à luz do dia. A Itália adicionou ciência à civilização ao desvendar o farol da justiça e considerar o criminoso na produção e na ação.] Toda moderna crítica política e religiosa prescinde de Estados sujeitáveis [, redentores e igrejas sujeitáveis]. Ela examina toda a comunidade em ação e reconstrói o espetáculo da redenção. Se você fosse um filósofo da estética, tomaria nota de todas as minhas excentricidades porque aqui você vê o espetáculo do instinto estético em ação. O curso de filosofia deveria reservar um detetive para mim. (JOYCE, 1944, p.186 [Os colchetes mostram as partes omitidas da citação de McLuhan. O mesmo trecho é citado em "Joyce, Aquinas, and the Poetic Process", que mencionarei mais tarde, mas este omite frases diferentemente.])

Um comentário, então, continua:

O termo principal aqui, a vivissecção, a comunidade em ação, a reconstrução, o descobrimento, estão relacionados com todas as fases da estética de Joyce. (McLUHAN, 1943, p.51)

Contudo, essa ideia não está completamente desenvolvida neste artigo. Com o intuito de examiná-la, nós temos que nos referir a outro artigo que é totalmente dedicado à leitura de Stephen Hero, chamado "Joyce, Aquinas, and the Poetic Process" (1951). 
3.

Stephen Hero, um antigo manuscrito de Um retrato do artista quando jovem, descoberto postumamente, é a história do período de vida universitária do protagonista Steven Daedalus em torno de seu artigo "Art and Life", o qual deveria ser lido na universidade. Ainda que o conteúdo do próprio artigo não esteja diretamente presente nesse romance, podemos reconstruir a teoria estética de Stephen, manifestada a partir de seus fragmentos que surgem em suas conversas com amigos, mãe e professores. Assim, esse manuscrito com características fortemente biográficas chamou a atenção de estudiosos como sendo um importante documento para entender as primeiras visões de Joyce sobre a arte. Especialmente notável é a noção de "epifania" que se considera como tendo papel central na teoria estética de Stephen, e o artigo de McLuhan sobre Stephen Hero, "Joyce, Aquinas, and the Poetic Process", não é uma exceção a esse respeito. Por exemplo, McLuhan diz:

Para Joyce e Eliot toda arte é uma sombra da Encarnação e todo artista é dedicado a revelar, ou epifanizar, as assinaturas das coisas, então o nous poietikos está para a percepção e abstração da mesma forma que o artista está para a existência de forma geral [.] (McLUHAN, 1951, p.4)

Essa passagem compartilha com os supracitados primeiros artigos a idéia de uma relação analógica entre o processo de cognição humana e o processo de criação artística. Isto é, McLuhan insiste aqui que o artista lê na existência as inscrições de Deus e as revela da mesma maneira que o homem cria na mente a sombra do mundo pela faculdade do nous poietikos (intelecto criativo). O ponto significativo aqui é a idéia de que o processo poético está associado à teoria estética de Stephen Hero, mediado pelo termo "epifania". Mas o que "epifania" significa? A seguir, quero examinar mais a fundo isso no texto de Joyce.

A palavra "epifania" aparece primeiro perto da parte conclusiva de Stephen Hero. Numa tarde, andando por uma rua com seus pensamentos voltados para uma garota, Stephen ouve um fragmento da conversa entre um jovem casal que lhe dá "uma impressão intensa o suficiente para que esta aflija sua sensibilidade profundamente".

Essa trivialidade o faz pensar em juntar vários desses momentos num livro de epifanias. Por epifania ele quis dizer uma manifestação espiritual repentina, seja na vulgaridade de uma fala ou gesto, ou mesmo numa memorável fase da mente. Ele acreditava que estava destinado a um homem das letras registrar essa epifanias com extremo cuidado, ao perceber que eles próprios são os momentos mais delicados e evanescentes. (JOYCE, 1944, p.211)

A seguir, Stephen começa uma longa exposição acerca dessa teoria sobre a beleza para seu amigo Cranly, na qual discute como o artista atinge um momento que ele chama de epifania a partir de impressões triviais.

- Nenhuma teoria estética, insiste rigidamente Stephen, tem valor algum ao investigar com a ajuda do farol da tradição. [...] A faculdade da compreensão deve ser escrutinizada [sic] na ação. (JOYCE, 1944, p.212)

Assim como acontece com a já citada passagem que começa a frase, "o espírito moderno é vivisseccionado", Stephen claramente situa sua estética como uma teoria 
moderna, ao rejeitar "o farol da tradição". Lembremo-nos de que, comentando a citação anterior, McLuhan direciona sua atenção à expressão "comunidade em ação". Nessa citação, também, "A faculdade da compreensão deve ser escrutinizada na ação", a teoria da beleza de Stephen é uma teoria vivisseccionada. Depois dessa citação, ele continua sua explanação mencionando os três atributos da beleza segundo Thomás de Aquino, "integritas", "consonantia" e "claritas", e explicando-os como se eles fossem as três etapas que a mente precisa para atingir o estágio de epifania. Contudo, se tomarmos corretamente o comentário de McLuhan, ainda que a explanação de Stephen proceda passo a passo, não devemos imaginar que o processo voltado para um momento de epifania de fato se dê nessa ordem; pois, de acordo com McLuhan, "o momento de captura é uma epifania, um momento fora de um pacto de tempo, e é ao se colocar percepções complexas em foco durante tais momentos que os minotauros dos labirintos sempre são superados" (McLUHAN, 1951, p.9). A apreensão da beleza é cumprida ao se trazer a mente à ação, e quando ela estiver em ação, capturá-la vivisseccioná-la. Para colocarmos isso nos termos da seção anterior, significa capturar o "monólogo interior" e possibilitar uma "análise prolongada".

Com o objetivo de observar isso a partir de uma perspectiva diferente, é útil notar que McLuhan cita a passagem de Stephen Hero apresentada na parte anterior novamente em "Joyce, Aquinas, and the Poetic Process", e discute o que se segue:

\footnotetext{
O uso das palavras "excentricidades" e "detetive" aqui é preciso e significativo. De uma lado, a imagem de labrintu [sic] é utilizada em todo lugar por Joyce como o arquétipo da cognição e da apreensão estética, e de outro o moderno detetive desde Poe emprega a técnica de refazer os passos com o objetivo de reconstruir uma ação exatamente como ela ocorreu. Edgar Poe é corretamente considerado na França o pai do simbolismo porque ele foi o primeiro a formular o processo poético como uma descoberta que resulta de refazer os seus passos. (McLUHAN, 1951, p.8)
}

O ato de captura do processo poético ao serem refeitos os seus passos é aqui trazido em relevo pela palavra "detetive". McLuhan se refere a Poe como a pessoa que formulou esse processo pela primeira vez, não apenas por ele ser "o pai das histórias de detetive", mas possivelmente também por causa de seu famoso ensaio "A Filosofia da Composição". Nesse texto, Poe descreve o método de escrita de um poema no qual o autor determina de antemão um efeito levado à mente do leitor depois de ler o poema, e passa a escrevê-lo no sentido inverso, a partir do fim em direção ao começo, para atingir tal efeito. Para parafrasear isso nos termos de McLuhan, esse é o método de capturar o "processo poético" de um leitor, vivisseccioná-lo, e, então, reconstruí-lo. Desnecessário dizer, uma história de detetive com mistério e solução, da mesma forma, é escrita ao se refazer a história toda dedutivamente a partir do macete pelo qual um detetive descobre o criminoso. O detetive é uma figura na qual esta técnica específica de retraçar os passos e reconstruí-los é dada forma. Com o objetivo de observar esse aspecto de forma mais detida, indico outro artigo, "Footprints in the Sand of Crime" (1946).

Nesse estudo, escrito na fase inicial de sua carreira se comparado a "Tradição de Edgar Poe", McLuhan tenta traçar a genealogia do detetive até a virtude renascentista do Homem Universal, e mais além até a eloquência ciceroniana com o objetivo de "prover 
um detetive com pedigree" (McLUHAN, 1946, p.620). A ambição por trás dessa tentativa é destacar os aspectos mais interessantes de uma história de detetives em detrimento dos clichês semelhantes a "[um] relaxamento comum para as mentes nobres" ou "uma prevenção para a fúria reprimida". Com um estilo cheio de afetações e expressões labirínticas típicas de eruditos jovens e ambiciosos, esse artigo não atinge necessariamente seu propósito. Entretanto, ao se referir ao breve texto de Poe, The Maelstrom, McLuhan faz uma observação interessante na parte final.

\begin{abstract}
O marinheiro na história The Maelstrom é primeiro paralisado pelo horror. Mas em sua própria paralisia existe uma outra fascinação que emerge, um poder de observação distanciada que se torna um interesse "científico" pela ação da tempestade. E isso proporciona seus meios de fuga. Assim como tudo em Poe, a narração avança de maneira casual e sem demora. Como a conversa de um polido homem do mundo. Mas nessa parábola Poe preserva o mistério do próprio detetive. Seu marinheiro escapa da tempestade por um truque de análise. $\mathrm{O}$ detetive produz o assassino da mesma forma. E ao mesmo tempo o detetive também permite ao leitor “escapar” do horror de seu próprio mundo ao conferir a ele o sentido de poder de distanciamento associado à atitude científica. Nessa medida, a história de detetive ao menos deve ser considerada a fórmula da felicidade que Swift destacou como querida pelo homem - a capacidade de ser perpetuamente bem ludibriado. (McLUHAN, 1946, p.634)
\end{abstract}

Em The Maelsrom, um marinheiro está envolvido num redemoinho, gradativamente se movendo para o centro da trajetória em espiral, até que começa então a observar coisas como pedaços de madeira que estão no turbilhão junto dele. Gradualmente, o sentimento de horror pelo redemoinho do qual ninguém sobrevive começa a ser substituído em sua mente pela curiosidade sobre a lei que governa o caminho dos estilhaços e, por isso, ele consegue escapar do redemoinho. De acordo com McLuhan, essa parábola "preserva o mistério do detetive", como se fosse oferecida para a dissecação. Ou seja, ele afirma que isto é o "poder de distanciamento associado à atitude científica" que dá ao detetive conhecimento e permite a ele capturar o processo de um crime, retraçá-lo e compreendê-lo estruturalmente. A partir desse ponto de vista, o conhecimento do detetive tem exatamente a mesma estrutura da compreensão vivisseccionada da beleza de Stephen.

Mas como se dão a vivisseção e a compreensão detetivesca? Esse é o problema que permanece. Apesar de eu ainda não estar na posição de dar a esse problema uma resposta clara, quero abrir uma perspectiva para ele ao colocar a discussão apresentada até aqui em ordem. Quando vista como um método, podemos resumir a apreensão estética elaborada por McLuhan no processo de interpretação do modernismo literário a partir de dois aspectos: primeiramente, justapor configurações de diferentes períodos; e, em segundo lugar, tematizar o "encontro" de diferentes meios de um mesmo período. Como é observado no modo como ele associa poetas metafísicos e simbolistas, essas duas operações se mesclam. Isso quer dizer que, entre a relação dos meios A e B em certo período e aquela entre A' e B' em outro, uma relação proporcional adicional é colocada $\left(\mathrm{A}: \mathrm{B}=\mathrm{A}^{\prime}: \mathrm{B}^{\prime}\right)$. O ponto fundamental nesse tipo de abordagem analógica baseia-se em colocar-se fora de certo ambiente, isto é, com um "poder de distanciamento associado à atitude científica". Para executar uma vivissecção em uma configuração de determinado período, deve-se sair e observá-lo a partir da configuração de um período diferente. Nesse sentido, o novo encontro dos meios na época contemporânea deve ser entendido numa 
relação analógica com o encontro entre a mídia oral e a mídia tipográfica na Renascença. Ou, para relacionar outra expressão a um assunto essencialmente equivalente, para se compreender a configuração de um ambiente determinado por um certo meio, deve-se sair desse determinado ambiente e posicionar esse meio numa relação translacional com outro meio. A forma compelida inconscientemente pelo meio tipográfico deve ser trazida para a consciência ao ser traduzida para um outro meio que é o cinema.

O ponto importante de tal método é seu caráter heurístico, uma vez que a relação proporcional entre diferentes configurações não são oferecidas de antemão. Então, McLuhan faz uma aposta ao conectar diferentes configurações e instituir uma relação translacional entre elas. Não se pode dizer em que condições essas apostas têm sucesso. O que se pode fazer é uma autópsia das várias observações de McLuhan para que se saiba em que fase elas tiveram sucesso e em que fase elas fracassaram.

4.

Em 1959, McLuhan publicou um artigo chamado "Myth and Mass Media". No ano seguinte, com um financiamento da National Association of Educational Media of the United States, ele apresentou o "Report on Project in Understanding New Media", que serviu como manuscrito para Understanding Media, publicado quatro anos mais tarde. O tempo de ele começar a produzir numerosas teses sobre mídia a toda velocidade se aproximava. Nesse ensaio, que foi escrito às vésperas de ele se tornar o herói da mídia, de certa forma, ele tomou novamente a ideia de transformação que a alfabetização trouxe para a nossa sensibilidade. Ele começa esse ensaio redefinindo o conceito de "mídia". Isto é, quando surge o tópico "meios de comunicação de massa", as pessoas sempre prestam atenção nos novos meios, como telégrafo, telefone, cinema, rádio e televisão, mas, de acordo com McLuhan, "o próprio inglês é um meio de massa, assim como qualquer idioma empregado por qualquer sociedade” (McLUHAN, 1959, p.339). Essa não é uma nova ideia para nós que já vimos os artigos precedentes de McLuhan: isto é, a idea de que uma língua já é em si mesma um meio, sem importar se está na forma falada ou escrita. Mas, nesse artigo, McLuhan dá um passo adiante.

Se uma língua inventada e utilizada por muitas pessoas é uma mídia de massa, qualquer uma de nossas novas mídias é em algum sentido uma nova linguagem, uma nova codificação da experiência coletiva alcançada por novos hábitos de trabalho e consciência coletiva inclusiva. Mas quando uma nova codificação atingiu o estágio tecnológico de comunicabilidade e repetibilidade, ela não se torna, como a língua falada, também um macromito? (McLUHAN, 1959, p.339-340)

Isto é, ele reverte a idéia de conceber a língua como um meio, declarando que qualquer meio é uma linguagem. Não há necessidade de destacarmos novamente um erro lógico. Ainda assim, é tal reversão lógica que traz novas abordagens mais adiante. Se qualquer meio é uma língua, essa "nova codificação da experiência" permaneceria, é claro, inconsciente. Entretanto, a situação na qual vários meios estão em conflito entre si, o "encontro" dos meios, oferece uma chance de capturar um processo de codificação como esse, condensado como um mito, e trazê-lo à consciência. $\mathrm{Na}$ direção dessa possibilidade, McLuhan a partir daí se comportaria como um vivisseccionador da mídia e detetive dos meios. É a mensagem de um meio que está a ser 
explorado, mas, é desnecessário dizer, aqui acontece uma outra derrapada lógica. Depois de alguns parágrafos, McLuhan escreve: 'Uma outra maneira de chegar a esse aspecto da linguagem como macromito é dizer que o meio é a mensagem” (McLUHAN, 1959, p.340; grifo meu).

\section{Notas}

${ }^{1}$ Traduzido por Fabiano Curi, revisado por Tauan Tinti.

2 Para exemplos, veja-se os seguintes trabalhos: John Fekete, The Critical Twilight: Explorations in the Ideology of AngloAmerican Literary Theory from Eliot to McLuhan (Routledge, 1978); Glenn Willmott, McLuhan, or Modernism in Reverse (University of Toronto Press, 1996).

${ }^{3}$ Para se aprofundar, também na discussão acima mencionada em "Joyce, Mallarmé, and the Press" - de que a poesia moderna deve muito à nova "tecnologia pictórica”, o cinema assim como o jornal (com imagens) - é modelo exemplar dessa nova mídia visual. Ele comenta, por exemplo, no mesmo artigo sobre "Eidophusikon”, é um equipamento mais antigo de panorama inventado por De Loutherbourg em 1781, como "a invenção do cinema” (p.44). Esse status do cinema como uma nova mídia seria direcionado para a televisão em seus principais escritos na década de 1960.

${ }^{4}$ Para exemplos, veja-se Robert Humphrey, Stream of Consciousness in the Modern Novel (Berkeley: University of California Press, 1954); Erwin R. Steinberg, The Stream of Consciousness and Beyond in Ulysses (University of Pittsburgh Press, 1973).

\section{Referências Bibliográficas}

ELIOT, T. S. “The Metaphysical Poets”. In: Selected Essays 1917-1932. Nova York: Houghton Mifflin Harcourt, 1932, p.241-250.

."Ulysses, Order, and the Myth". In: Selected Prose of T. S. Eliot, ed. Frank Kermode. Londres: Faber, 1975, p.175-178.

FEKETE, John. The Critical Twilight. Explorations in the Ideology of Anglo-American Literary Theory from Eliot to McLuhan. Londres: Routledge, 1978.

HUMPHREY, Robert. Stream of Consciousness in the Modern Novel. Berkeley: University of California Press, 1954.

JAMES, William. The Principles of Psychology (1890). Chicago: Encyclopaedia Britannica, 1952, p.224-225.

JOYCE, James. Stephen Hero. Nova York: New Directions, 1944.

McLUHAN, Herbert Marshall. “Joyce, Mallarmé, and the Press”, Sewanee Review 62 (1943): 39 (Reimpresso em: McLuhan, Interior Landscape).

."Edgar Poe's Tradition,” Sewanee Review 52 (1944).

.Footprints in the Sands of Crime". In: Sewanee Review 54 (1946).

."Joyce, Aquinas, and the Poetic Process". In: Renascence 4 (1951).

."Sight, Sound and the Fury: The New Media of Mass-communications are Having a Revolutionary

Effect on Society and Culture”. In: Commonweal 60 (1954), p.7-11.

."Myth and Mass Media". In: Daedalus 88 (1959).

.The Gutenberg Galaxy: The Making of Typographic Man. Toronto: University of Toronto Press, 1962.

.The Interior Landscape: The Literary Criticism of Marshall McLuhan 1943-1962, ed. Eugene McNamara.

Nova York: McGraw-Hill, 1969.

STEINBERG, Erwin R. The Stream of Consciousness and Beyond in Ulysses. Pittsburgh: University of Pittsburgh Press, 1973.

WILLMOTT, Glenn. McLuhan, or Modernism in Reverse. Toronto: University of Toronto Press, 1996. 